\title{
Role of Oral Pregabalin as Premedication in Attenuation of Hemodynamic Responses to Laryngoscopy, Intubation, and Extubation in Patients Undergoing Laparoscopic Cholecystectomy: A Randomized Clinical Trial
}

\author{
Sudhir Sachdev ${ }^{1}$, Aman Malawat $^{2}$, Durga Jethava ${ }^{3}$, Shubhra Gupta ${ }^{4}$, Khayyam Moin ${ }^{5}$
}

\begin{abstract}
Background and aim: Direct laryngoscopy, tracheal intubation, and extubation contribute to augmentation in heart rate and blood pressure. This can precipitate serious complications in patients with coronary artery disease, intracranial neuropathology, or reactive airways. Attenuation of hemodynamic stress response to laryngoscopy, intubation, and extubation is essential for better anesthetic outcome. The aim of this study was to evaluate the effect of oral pregabalin as premedication in attenuation of hemodynamic stress response to laryngoscopy, intubation, and extubation.

Materials and methods: This prospective randomized double-blinded placebo controlled study was conducted with 60 patients of American Society of Anesthesiologists (ASA) physical status class I/II, undergoing elective laparoscopic cholecystectomy. Patients were allocated randomly into two groups receiving either oral placebo or oral pregabalin $150 \mathrm{mg}, 120$ minutes before induction of anesthesia. Hemodynamic parameters such as heart rate, systolic, diastolic, and mean blood pressures were compared at various time points.

Results: Pregabalin showed a significant attenuation of hemodynamic stress response to laryngoscopy, tracheal intubation, and extubation compared with that of placebo. The pregabalin premedicated patients remained hemodynamically stable perioperatively without any significant side effects.

Conclusion: Pregabalin is effective in attenuating hemodynamic stress response to laryngoscopy, tracheal intubation, and extubation.

Keywords: Extubation, Hemodynamic, Intubation, Laryngoscopy, Pregabalin.

Journal of Mahatma Gandhi University of Medical Sciences \& Technology (2019): 10.5005/jp-journals-10057-0094
\end{abstract}

\section{INTRODUCTION}

Laryngoscopy, tracheal intubation, and extubation are associated with various cardiovascular changes such as hypertension, tachycardia, dysrhythmias, and increased circulating catecholamines. ${ }^{1}$ The effect although is transient, from 30 seconds after intubation to up to 10 minutes. ${ }^{2}$ It occurs because of adrenergic response which leads to stimulation of the cardioaccelerator fibers.

Endotracheal intubation is well tolerated by normotensive patients, but even transient stimulation has been associated with increased morbidity and mortality in patients with preeclampsia, recent myocardial infarction, hypertension, and cerebrovascular pathology such as aneurysms, tumors, or raised intracranial pressure. ${ }^{3,4}$

Complications like dysrhythmias, intracranial bleed, myocardial ischemia, pulmonary edema, and cerebral hemorrhage can occur due to stress response during anesthetic procedures like laryngoscopy, intubation, and extubation which may increase the blood pressure by $40-50 \%$ and heart rate by $20 \%{ }^{5,6}$

Laparoscopy is a technique for visualization of the internal organs of abdomen or pelvis with an aid of camera using small incisions for ports which became very popular in early 1990s because less postoperative complications and pain were noted when compared with open cholecystectomy.

The pneumoperitoneum caused due to $\mathrm{CO}_{2}$ insufflation further adds to several homeostatic alterations in acid-base balance, cardiovascular, pulmonary physiology, and stress responses. ${ }^{7}$

\begin{abstract}
${ }^{1-5}$ Department of Anaesthesiology, Critical Care and Pain Management, Mahatma Gandhi Medical College and Hospital, Mahatma Gandhi University of Medical Sciences and Technology, Jaipur, Rajasthan, India Corresponding Author: Aman Malawat, Department of Anaesthesiology, Critical Care and Pain Management, Mahatma Gandhi Medical College and Hospital, Mahatma Gandhi University of Medical Sciences and Technology, Jaipur, Rajasthan, India, Phone: +91 7737200883, e-mail:dr.a.malawat@gmail.com
\end{abstract}

How to cite this article: Sachdev S, Malawat A, Jethava D, et al. Role of Oral Pregabalin as Premedication in Attenuation of Hemodynamic Responses to Laryngoscopy, Intubation, and Extubation in Patients Undergoing Laparoscopic Cholecystectomy: A Randomized Clinical Trial. J Mahatma Gandhi Univ Med Sci Tech 2019;4(1):1-6.

Source of support: Nil

Conflict of interest: None

Premedication in the form of vasodilators, adrenoreceptor blockers, calcium channel blockers, and opioids was used earlier to attenuate these responses, with variable results. ${ }^{8-13}$

Pregabalin, a gabapentinoid compound appears to produce an inhibitory modulation of neuronal excitability particularly in neocortex, amygdala, and hippocampus of central nervous system. ${ }^{14,15}$

However, there are evidences suggesting that perioperative administration is effective in attenuation of the hemodynamic

(c) The Author(s). 2019 Open Access This article is distributed under the terms of the Creative Commons Attribution 4.0 International License (https://creativecommons. org/licenses/by-nc/4.0/), which permits unrestricted use, distribution, and non-commercial reproduction in any medium, provided you give appropriate credit to the original author(s) and the source, provide a link to the Creative Commons license, and indicate if changes were made. The Creative Commons Public Domain Dedication waiver (http://creativecommons.org/publicdomain/zero/1.0/) applies to the data made available in this article, unless otherwise stated. 
stress response to laryngoscopy intubation and extubation and preventing chronic postoperative pain, nausea, vomiting, and delirium. ${ }^{16}$ Only limited literature is available related to the cardiovascular properties of pregabalin in patients undergoing laparoscopic surgery. Hence, this study was designed to evaluate the effect of oral pregabalin in attenuation of hemodynamic stress response during laryngoscopy, intubation, and extubation in patients undergoing laparoscopic cholecystectomy. The primary objective was to study the hemodynamic changes (heart rate, systolic, diastolic, and mean blood pressure) associated with laryngoscopy, tracheal intubation, and extubation.

\section{Materials and Methods}

This prospective randomized double-blinded placebo controlled study was conducted after obtaining permission from the institutional ethics committee and informed consent from all the patients.

Sixty patients were randomly divided into two equal groups using a computer generated list. Group C (control group) received oral placebo in the form of oral multivitamin capsule, 120 minutes before surgery. Group P (pregabalin group) received oral pregabalin 150 mg, 120 minutes before surgery. Each patient was given either drug based on the generated list in a sealed, opaque envelope by the preoperative nurse. Both patient and investigator were unaware of the type of administered drug. Moreover, the nurse giving the drugs in the preoperative area was unaware of the study.

Inclusion criteria were patients belonging to the ASA physical status class I/II, aged 18 to 65 years and scheduled for laparoscopic cholecystectomy under general anesthesia. Exclusion criteria were patients with hypertension, diabetes, psychiatric illness, intake of sedatives, antipsychotics, and antiepileptic drugs; obesity; and drug allergy. Likewise, pregnant, lactating females, patients with anticipated difficult intubation, and those requiring more than one attempt or more than 20 seconds for laryngoscopy were excluded from the study. On day of surgery, the study drugs were given with a sip of water 120 minutes before induction of anesthesia. Continuous monitoring of the heart rate, blood pressure, and arterial oxygen saturation $\left(\mathrm{SpO}_{2}\right)$ was done in the preoperative period every 5 minutes by the nurse in charge of the preoperative room.

In the operation theater, standard 5-lead electrocardiography, noninvasive blood pressure and pulse oximetry were attached, and baseline parameters were recorded. Venous access was secured using an $18-G$ cannula on the dorsum of the nondominant hand. Injection midazolam $1 \mathrm{mg}$ and fentanyl $1 \mu \mathrm{g} / \mathrm{kg}$ were given. Preoxygenation was done for 3 minutes and then proceeded for induction with propofol $2 \mathrm{mg} / \mathrm{kg}$ intravenously mixed with preservative-free lignocaine hydrochloride. Succinylcholine was used intravenously $2 \mathrm{mg} / \mathrm{kg}$ to facilitate endotracheal intubation with proper sized welllubricated cuffed endotracheal tube. Laryngoscopy and tracheal intubation was done by the same person each time with appropriate sized, cuffed endotracheal tube. Anesthesia was maintained with inhalation of isoflurane 1 minimum alveolar concentration; nitrous oxide:oxygen 40:60. Muscle relaxation was attained with vecuronium bromide in the dose of $0.06-0.08 \mathrm{mg} / \mathrm{kg}$ intravenously as loading dose and $25 \%$ of the initial dose as maintenance doses. After completion of the surgery, neostigmine $60 \mu \mathrm{g} / \mathrm{kg}$ and glycopyrrolate $10 \mu \mathrm{g} / \mathrm{kg}$ were administered intravenously to reverse the residual neuromuscular blockade.

Hemodynamic parameters such as heart rate, systolic, diastolic, and mean blood pressures were recorded before the administration of drug (baseline), at laryngoscopy and intubation, at 1, 3, and 5 minutes after intubation, before pneumoperitoneum, 15 and 30 minutes after pneumoperitoneum, after release of $\mathrm{CO}_{2}$, and after extubation.

In the postanesthesia care unit, the patients received the standard postoperative care including oxygen administration via face mask at 4-6 L/minute and monitoring of heart rate, noninvasive blood pressure (NIBP), respiratory rate, and $\mathrm{SpO}_{2}$. We observed for any episodes of bradycardia, headache, nausea, vomiting, restlessness, arrhythmias, and hypotension till 24 hours postoperatively.

The primary outcome measure was to compare hemodynamic parameters at laryngoscopy, intubation, and extubation. The secondary outcomes were to evaluate the distribution of complications.

\section{Statistical Analyses}

The sample size was calculated using the formula: $(n=[z(1-\alpha / 2)] 2 \times$ $\mathrm{SD} 2 / d 2)$

where

$z(1-\alpha / 2)=$ standard normal deviate for $95 \%$ confidence $=1.96$

$\mathrm{SD}=$ standard deviation of mean arterial pressure $(\mathrm{MAP})=$ $14 \mathrm{~mm} \mathrm{Hg}$

$d=$ precision $=5 \%$

$n=1.962 \times 142 / 52$

$n=30$

The sample size obtained was 30 patients in each group.

A statistical analysis was performed using SPSS for Windows (version 16.0, 2007; SPSS, Inc., Chicago, IL, USA). Data are expressed as mean, intragroup difference was evaluated by two-way analysis of variance, and intergroup using $t$ test. $p$ values of $<0.05$ were considered significant.

\section{Results}

A total of 60 patients were enrolled in the study, and none were excluded as shown in consort chart (Flowchart 1). Demographics of both the groups were comparable in terms of age, weight, sex, duration of surgery, and ASA physical status classification (Table 1).

Systolic blood pressure was higher from baseline values in control group during laryngoscopy and intubation ( $p=0.0215)$. Thereafter, this upsurge remained persistent throughout the surgery at all points of time until after extubation $(p<0.0001)$. In the pregabalin group, there was no increment, and the patients were stable at all points of time after giving the study drug (Table 2A). Similar trends were observed for diastolic and mean blood pressure (Tables 2B and 2C).

There was a significant increase in heart rate from baseline values during laryngoscopy and intubation in both the groups ( $p=0.0025$ ) which returned to previous values within 3 minutes in pregabalin group when compared with 5 minutes in the control group. Thereafter, the heart rate was maintained below the baseline value at all time points except after extubation in the patients receiving pregabalin. While in the control group, the rise in heart rate persisted throughout the surgery with significantly increased trend after $\mathrm{CO}_{2}$ release $(p=0.0328)$ and after extubation $(p=0.0017)$ (Table 2D).

The comparison of $\mathrm{SpO}_{2}$ in-between both the groups showed that the mean value of $\mathrm{SpO}_{2}$ was slightly higher in pregabalin 
Flowchart 1: Consort flow diagram

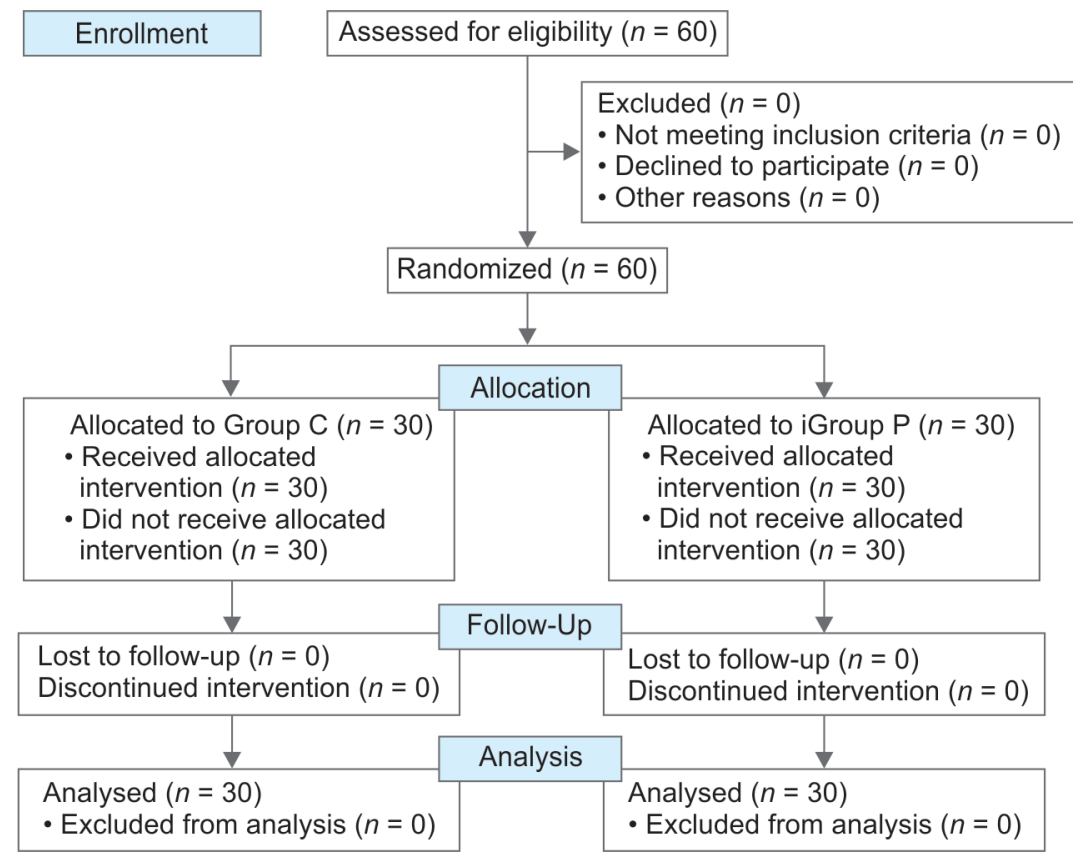

Table 1: Demographic data

\begin{tabular}{|c|c|c|c|}
\hline \multirow[b]{2}{*}{ Parameters } & \multicolumn{2}{|c|}{ Mean $\pm S D$} & \multirow[b]{2}{*}{$p$} \\
\hline & Group C $(n=30)$ & Group $P(n=30)$ & \\
\hline Age (years) & $36.5 \pm 12.01$ & $34.7 \pm 14.82$ & $0.6073^{\#}$ \\
\hline \multicolumn{4}{|l|}{$\operatorname{Sex}(\%)$} \\
\hline Male & $12(40)$ & $12(40)$ & $1^{*}$ \\
\hline Female & $18(60)$ & $18(60)$ & \\
\hline Weight (kg) & $58.4 \pm 6.6$ & $60.9 \pm 5.9$ & $0.1274^{\#}$ \\
\hline Duration of surgery (min) & $59.6 \pm 5.4$ & $61.3 \pm 5.6$ & $0.2362^{\#}$ \\
\hline \multicolumn{4}{|l|}{ ASA grade (\%) } \\
\hline I & 13 & 16 & $0.606^{*}$ \\
\hline$\|$ & 17 & 14 & \\
\hline
\end{tabular}

*Fisher's exact test; \#unpaired $t$ test; $n$, number of patients; SD, standard deviation; ASA, American Society of Anesthesiologists

Table 2A: Comparison of SBP in different time intervals in-between groups

\begin{tabular}{|c|c|c|c|c|c|}
\hline \multirow[b]{2}{*}{$S B P$} & \multicolumn{2}{|c|}{ Pregabalin group } & \multicolumn{2}{|c|}{ Control group } & \multirow[b]{2}{*}{$p^{*}$} \\
\hline & Mean & $S D$ & Mean & $S D$ & \\
\hline Baseline & 128.2 & 21.86 & 124.64 & 5.8 & 0.3922 \\
\hline During laryngoscopy and intubation & 133.73 & 9.384 & 138.51 & 5.89 & 0.0215 \\
\hline 1 minute & 124.7 & 11.36 & 141.11 & 11.55 & $<0.0001$ \\
\hline 3 minutes & 116.1 & 23.24 & 133.23 & 6.86 & 0.0003 \\
\hline 5 minutes & 117 & 9.137 & 130.7 & 6.87 & $<0.0001$ \\
\hline Before pneumoperitoneum & 114.2 & 8.823 & 128.54 & 9.23 & $<0.0001$ \\
\hline 15 minutes after pneumoperitoneum & 126.7 & 7.597 & 144.21 & 7.02 & $<0.0001$ \\
\hline 30 minutes after pneumoperitoneum & 124.6 & 6.831 & 140.21 & 8.64 & $<0.0001$ \\
\hline After $\mathrm{CO}_{2}$ release & 127.9 & 8.501 & 146.34 & 7.21 & $<0.0001$ \\
\hline After extubation & 135.3 & 6.389 & 149.67 & 8.34 & $<0.0001$ \\
\hline
\end{tabular}

*Unpaired $t$ test; SD, standard deviation; SBP, systolic blood pressure

group when compared with the control group. The difference was statistically significant at various time points (Table 2E).
In the control group, two patients had episode of nausea and vomiting; two patients reported restlessness in the immediate 
Table 2B: Comparison of DBP in different time intervals in-between groups

\begin{tabular}{|c|c|c|c|c|c|}
\hline \multirow[b]{2}{*}{$D B P$} & \multicolumn{2}{|c|}{ Pregabalin group } & \multicolumn{2}{|c|}{ Control group } & \multirow[b]{2}{*}{$p^{*}$} \\
\hline & Mean & $S D$ & Mean & $S D$ & \\
\hline Baseline & 83.47 & 8.046 & 81.88 & 4.53 & 0.3492 \\
\hline During laryngoscopy and intubation & 86.53 & 8.299 & 91.11 & 4.7 & 0.0108 \\
\hline 1 minute & 79.43 & 9.008 & 96.54 & 6.11 & $<0.0001$ \\
\hline 3 minutes & 76.13 & 8.153 & 89.28 & 3.8 & $<0.0001$ \\
\hline 5 minutes & 73.8 & 7.631 & 86.54 & 3.44 & $<0.0001$ \\
\hline Before pneumoperitoneum & 73.07 & 8.111 & 84.31 & 5.24 & \\
\hline 15 minutes after pneumoperitoneum & 84.97 & 7.01 & 90.23 & 3.9 & 0.0007 \\
\hline 30 minutes after pneumoperitoneum & 84.3 & 7.34 & 90.01 & 4.9 & 0.0008 \\
\hline After $\mathrm{CO}_{2}$ release & 85.53 & 6.35 & 92.67 & 6.45 & 0.0001 \\
\hline After extubation & 89.7 & 6.221 & 98.56 & 6.23 & $<0.0001$ \\
\hline
\end{tabular}

*Unpaired $t$ test; SD, standard deviation; DBP, diastolic blood pressure

Table 2C: Comparison of MAP in different time intervals in-between groups

\begin{tabular}{|c|c|c|c|c|c|}
\hline \multirow[b]{2}{*}{ MAP } & \multicolumn{2}{|c|}{ Pregabalin group } & \multicolumn{2}{|c|}{ Control group } & \multirow[b]{2}{*}{$p^{*}$} \\
\hline & Mean & $S D$ & Mean & $S D$ & \\
\hline Baseline & 99.63 & 7.218 & 96.11 & 4.72 & 0.0291 \\
\hline During laryngoscopy and Intubation & 102.23 & 5.469 & 105.28 & 4.5 & 0.0216 \\
\hline 1 minute & 94.5 & 9.273 & 111.34 & 7.11 & $<0.0001$ \\
\hline 3 minutes & 90.7 & 8.879 & 103.88 & 4.26 & $<0.0001$ \\
\hline 5 minutes & 88.7 & 7.493 & 101.18 & 4.2 & $<0.0001$ \\
\hline Before pneumoperitoneum & 86.73 & 8.004 & 98.34 & 6.34 & $<0.0001$ \\
\hline 15 minutes after pneumoperitoneum & 98.9 & 6.557 & 103.67 & 5.78 & 0.0041 \\
\hline 30 minutes after pneumoperitoneum & 97.67 & 6.609 & 102.23 & 4.88 & 0.0035 \\
\hline After $\mathrm{CO}_{2}$ release & 99.83 & 6.012 & 104.9 & 4.34 & 0.0004 \\
\hline After extubation & 104.4 & 5.531 & 112.35 & 5.39 & $<0.0001$ \\
\hline
\end{tabular}

*Unpaired $t$-test; SD, standard deviation; MAP, mean arterial pressure

Table 2D: Comparison of heart rate in different time interval in-between groups

\begin{tabular}{|c|c|c|c|c|c|}
\hline \multirow[b]{2}{*}{ Heart rate } & \multicolumn{2}{|c|}{ Pregabalin group } & \multicolumn{2}{|c|}{ Control group } & \multirow[b]{2}{*}{$p^{*}$} \\
\hline & Mean & $S D$ & Mean & $S D$ & \\
\hline Baseline & 87.17 & 8.914 & 85 & 5.77 & 0.2675 \\
\hline During laryngoscopy and intubation & 95.33 & 8.014 & 88.41 & 8.9 & 0.0025 \\
\hline 1 minute & 89.8 & 9.622 & 90.88 & 11.66 & 0.697 \\
\hline 3 minutes & 86.97 & 11.17 & 87.51 & 8.92 & 0.8368 \\
\hline 5 minutes & 83.83 & 11.08 & 85.08 & 8.37 & 0.6238 \\
\hline Before pneumoperitoneum & 82.83 & 9.454 & 85.92 & 10.61 & 0.2384 \\
\hline 15 minutes after pneumoperitoneum & 86.83 & 7.852 & 89.67 & 8.54 & 0.1851 \\
\hline 30 minutes after pneumoperitoneum & 83.7 & 9.763 & 87.45 & 8.23 & 0.1131 \\
\hline After $\mathrm{CO}_{2}$ release & 83.47 & 9.641 & 88.58 & 8.42 & 0.0328 \\
\hline After extubation & 89.6 & 5.587 & 94.89 & 6.78 & 0.0017 \\
\hline
\end{tabular}

*Unpaired $t$ test; SD, standard deviation

postoperative period. In the pregabalin group, two patients had bradycardia; one patient had nausea and vomiting in the postoperative period. None of the patients had headache, arrhythmia, or hypotension (Table 3). Out of total 30 participants included in each study group, none had to be dropped off.

\section{Discussion}

Airway management is one of the core skills of the anesthesiologist, via face mask ventilation, insertion of a laryngeal mask airway, endotracheal intubation by direct or indirect (video-assisted) laryngoscopy, or by use of a fiberscope. Pain relieving agents are usually administered with the concept of balanced analgesia, which involves a combination of analgesics with either synergistic or additive effects.

During laryngoscopy and intubation, there is a rise in both heart rate and blood pressure due to stimulation of sympathetic nervous system. A study conducted by Bruder et al. ${ }^{6}$ showed that there is an average increase of $20 \%$ in heart rate and $40-50 \%$ in blood pressure from the baseline values. Similar hemodynamic 
Table 2E: Comparison of $\mathrm{SpO}_{2}$ in different time intervals in-between groups

\begin{tabular}{|c|c|c|c|c|c|}
\hline \multirow[b]{2}{*}{$\mathrm{SpO}_{2}$} & \multicolumn{2}{|c|}{ Pregabalin group } & \multicolumn{2}{|c|}{ Control group } & \multirow[b]{2}{*}{$p^{*}$} \\
\hline & Mean & $S D$ & Mean & $S D$ & \\
\hline Baseline & 99.7 & 0.4661 & 99.5 & 0.47 & 0.1012 \\
\hline During laryngoscopy and intubation & 99.67 & 0.4795 & 99.4 & 0.46 & 0.0283 \\
\hline 1 minute & 99.8 & 0.4068 & 99.56 & 0.48 & 0.0397 \\
\hline 3 minutes & 99.63 & 0.4901 & 99.7 & 0.44 & 0.5627 \\
\hline 5 minutes & 99.7 & 0.4661 & 99.81 & 0.47 & 0.3634 \\
\hline Before pneumoperitoneum & 99.6 & 0.4983 & 99.54 & 0.48 & 0.6337 \\
\hline 15 minutes after pneumoperitoneum & 99.67 & 0.4795 & 99.42 & 0.41 & 0.0321 \\
\hline 30 minutes after pneumoperitoneum & 99.8 & 0.4068 & 99.78 & 0.43 & 0.8593 \\
\hline After $\mathrm{CO}_{2}$ release & 99.73 & 0.4498 & 99.48 & 0.48 & 0.0398 \\
\hline After extubation & 99.76 & 0.4498 & 99.49 & 0.49 & 0.0286 \\
\hline
\end{tabular}

*Unpaired $t$ test; $\mathrm{SD}$, standard deviation; $\mathrm{SpO}_{2}$, oxygen saturation

Table 3: Distribution of complications

\begin{tabular}{lll}
\hline Complications & Pregabalin group & Control group \\
\hline Bradycardia & 2 & 0 \\
Headache & 0 & 0 \\
Nausea/vomiting & 1 & 2 \\
Restlessness & 0 & 2 \\
Arrhythmia & 0 & 0 \\
Hypotension & 0 & 0 \\
\hline
\end{tabular}

changes are also seen during creation of pneumoperitoneum in laparoscopic surgeries which was also showed in the study carried out by Odeberg et al. ${ }^{17}$ and Shorrab et al. ${ }^{18}$

Pregabalin is a drug with analgesic, anxiolytic, and anticonvulsant property mainly used for the treatment of neuropathic pain, postherpetic neuralgia, and epilepsy. It has been used in the preoperative setup to abolish the cardiovascular stress response occurring due to laryngoscopy and tracheal intubation but with vivid doses and conflicting outcomes. ${ }^{19-21}$

Thus, this study was undertaken to evaluate the effect of oral pregabalin as premedication in attenuation of hemodynamic stress response to laryngoscopy, intubation, and extubation in patients undergoing laparoscopic cholecystectomy.

Saxena et al. ${ }^{22}$ in a study to evaluate the effect of pregabalin premedication on response to laryngoscopy and intraoperative hemodynamic parameters in laparoscopic cholecystectomy observed that 150 and $300 \mathrm{mg}$ pregabalin were proportionately potent in abolishing the rise in heart rate in response to laryngoscopy and intubation. Another study by Rastogi et al. ${ }^{23}$ compared different doses of pregabalin to analyze the clinically potent and safe dose to maintain the hemodynamics during airway manipulation and observed the attenuation of MAP in the premedicated group was significant statistically, i.e., in pregabalin $75 \mathrm{mg}$ group $(97.80 \pm 2.52$ vs $110.70 \pm 4.94, p=0.001)$ and in pregabalin $150 \mathrm{mg}$ group (92.06 \pm 3.37 vs $110.70 \pm 4.94, p=0.001$ ) to when compared with the control group, in a dose-related manner. Hence, upon these evidences, a dose of $150 \mathrm{mg}$ pregabalin was selected for our study group.

We observed that pregabalin premedication provided a substantial trend of stability in all the hemodynamic parameters at all time points with negligible side effects. Our results were comparable with the observations made by Chakraborty et al., ${ }^{24}$ who concluded that $150 \mathrm{mg}$ of oral pregabalin safely blunts the hemodynamic response to laryngoscopy and intubation. Sundar et al. ${ }^{25}$ conducted a study to observe the effects of pregabalin premedication on attenuation of hemodynamic stress response to tracheal intubation. They also reported opioid-sparing effect in patients undergoing coronary artery bypass graft and concluded that pregabalin premedication was effective in abolishing reflex tachycardia in response to direct laryngoscopy and tracheal intubation. Similarly, in our study, although there was a significant rise in heart rate from baseline values during laryngoscopy and intubation in both the groups ( $p=0.0025)$, it returned to previous values within 3 minutes in the pregabalin group when compared to 5 minutes in the control group. Thereafter, heart rate was consistently maintained below the baseline value at all time points till after extubation in pregabalin group. These observations regarding heart rate trends were also in line with the observations reported by Singh et al. ${ }^{26}$ They evaluated the effects of pregabalin premedication for suppressing the stress response due to laryngoscopy and tracheal intubation and found that magnitude of increase in heart rate was lower, and it was falling below the basal value at 10 minutes in the pregabalin group, but in the control group, it did not reach the baseline value even by 10 minutes following direct laryngoscopy and tracheal intubation.

Eren et al. ${ }^{27}$ administered pregabalin to 50 patients undergoing elective spine surgery to analyze its effectiveness in abolishing the hemodynamic stress response to intubation. They found that MAP values were significantly curtailed in the pregabalin group compared with the control group $(108.3 \pm 6.3$ vs $119.4 \pm 9.8, p=$ 0.0001 ) during laryngoscopy and intubation even up to 10th minute. We also found that mean blood pressure was higher from baseline values in the control group when compared with the pregabalin group during laryngoscopy and intubation $(105.28 \pm 4.5$ vs $102.23 \pm$ $5.4, p=0.0215)$. Furthermore in the control group, this increase persisted throughout the surgery at all points of time until after extubation $(p<0.0001)$. While in the pregabalin group, the patients were stable at all points of time after the administration of the study drug. Similar trends of stability with the pregabalin group were observed for systolic and diastolic blood pressures.

From this study, we conclude that pregabalin $150 \mathrm{mg}$ seems to be an effective and safe drug to attenuate the sympathetic response to laryngoscopy, tracheal intubation, and extubation and can be useful for patients with comorbid conditions preoperatively. 


\section{References}

1. Russell WJ, Morris RG, Frewin DB, et al. Changes in plasma catecholamine concentrations during endotracheal intubation. $\mathrm{Br} J$ Anaesth 1981;53(8):837-839. DOI: 10.1093/bja/53.8.837.

2. Gupta A, Wakhloo R, Gupta V, et al. Comparison of esmolol and lignocaine for atttenuation of cardiovascular stress response to laryngoscopy and endotracheal intubation. JK Science 2009;11:0-3.

3. Channaiah VB, Chary K, VIk JL, et al. Low dose fentanyl: hemodynamic response to endotracheal intubation in normotensive patients. Arch Med Sci 2008:4(3):293-299.

4. Malde AD, Sarode V. Attenuation of the hemodynamic response to endotracheal intubation: fentanyl versus lignocaine. $\mathrm{Br} J$ Anaesth 1987;59(3):295-299. DOI: 10.1093/bja/59.3.295.

5. Edwards ND, Alford AM, Dobson PM, et al. Myocardial ischaemia during tracheal intubation and extubation. Br J Anaesth 1994;73(4):537-539. DOI: $10.1093 / \mathrm{bja} / 73.4 .537$.

6. Bruder N, Granthil C, Ortega D. Consequences and prevention methods of haemodynamic changes during laryngoscopy and intubation. Ann Fr Anaesth Reanim 1992;11(1):57-71. DOI: 10.1016/ s0750-7658(05)80321-1.

7. Das M, Ray M, Mukherjee G. Haemodynamic changes during laparoscopic cholecystectomy. effect of clonidine premedication. Indian J Anaesth 2007;51:205.

8. Fassoulaki A, Kaniaris P. Intranasal administration of nitroglycerine attenuates the Pressor response to laryngoscopy and intubation of the trachea. Br J Anaesth 1983;55(1):49-52. DOI: 10.1093/bja/55.1.49.

9. Miller DR, Martineau RJ, Wynands JE, et al. Bolus administration of esmolol for controlling the haemodynamic response to tracheal intubation: the canadian multicentre trial. Can J Anaesth 1991;38(7):849-858. DOI: 10.1007/BF03036959.

10. Kale SC, Mahajan RP, Jayalakshami TS, et al. Nifedipine prevents the pressor response to laryngoscopy and tracheal intubation in patients with coronary artery disease. Anaesthesia 1988;43(6):495-497. DOI: 10.1111/j.1365-2044.1988.tb06642.x.

11. Mikawa K, Ikegaki J, Maekawa N, et al. The effect of diltiazem on the cardiovascular response to tracheal intubation. Anaesthesia 1990;45(4):289-293. DOI: 10.1111/j.1365-2044.1990.tb14734.x.

12. Dahlgren N, Messeter K. Treatment of stress response to laryngoscopy and intubation with fentanyl. Anesthesia 1981;36(11):1022-1026. DOI: 10.1111/j.1365-2044.1981.tb08676.x.

13. Miller DR, Martineau RJ, O'brien $\mathrm{H}$, et al. Effects of alfentanil on the haemodynamic and catecholamine response to tracheal intubation. AnesthAnalg 1993;76(5):1040-1046. DOI: 10.1213/00000539199305000-00023.

14. Taylor CP, Angelotti T, Fauman E. Pharmacology and mechanism of action of pregabalin: the calcium channel alpha2-delta (alpha2-delta) subunit as a target for antiepileptic drug discovery. Epilepsy Res 2007;73(2):137-150. DOI: 10.1016/j.eplepsyres.2006.09.008.
15. Ben-Menachem E. Pregabalin pharmacology and its relevance to clinical practice. Epilepsia 2004;45(s6):13-18. DOI: 10.1111/j.00139580.2004.455003.x.

16. Rose MA, Kam PC. Gabapentin: pharmacology and its use in pain management. Anaesthesia 2002;57(5):451-462. DOI: 10.1046/j.00032409.2001.02399.x.

17. Odeberg $S$, Ljungqvist $O$, Svenberg $T$, et al. Haemodynamic effects of pneumoperitoneum and the influence of posture during anaesthesia for laparoscopic surgery. Acta Anaesthesiol Scand 1994;38(3): 276-283. DOI: 10.1111/j.1399-6576.1994.tb03889.x.

18. Shorrab AA, Demian AD, Shoma AM, et al. Five hours of insufflation in a bad position: anaesthetic implications. Saudi J Anaesth 2008;2(2):62.

19. McMahon AJ, Fischbacher CM, Frame SH, et al. Impact of laparoscopic cholecystectomy: A population-based study. Lancet 2000;356(9242):1632-1637. DOI: 10.1016/S0140-6736(00)03156-1.

20. Steven AD, Michael JB, Robert FB. Physiologic \& Pathophysiologic Responses to Intubation Benumof's Airway Management: Principles \& Practice. 2nd ed., Philadelphia: MOSBY Elsevier; 2007. pp. 193-212.

21. Talakoub R, Khodayari A, Saghaei M. Effect of controlled hyperventilation on the pressor response to laryngoscopy and tracheal intubation. Middle East J Anaesthesiol 2003;17(3): 403-413.

22. Saxena A, Gupta P, Chaudhary L. Effect of pregabalin premedication on the laryngoscopy response and intra-operative hemodynamic variables in laparoscopic cholecystectomy: a randomized comparison of two doses. Int J Sci Stud 2016;4:75-80.

23. Rastogi B, Gupta K, Gupta PK, et al. Oral pregabalin premedication for attenuation of haemodynamic pressor response of airway instrumentation during general anaesthesia: a dose response study. Indian J Anaesth 2012;56(1):49-54. DOI: 10.4103/0019-5049.93344.

24. Chakraborty R, Jain R, Sharma R. Evaluation of the efficacy of preoperative oral pregabalin in attenuating hemodynamic response to laryngoscopy and intubation and on post-operative pain in patients undergoing elective surgery under general anaesthesia. Indian J Clin Anaesthe 2016;3(3):419-426. DOI: 10.5958/2394-4994.2016. 00071.8 .

25. Sundar AS, Kodali R, Sulaiman S, et al. The effects of preemptive pregabalin on attenuation of stress response to endotracheal intubation and opioid-sparing effect in patients undergoing off-pump coronary artery bypass grafting. Ann Card Anaesth 2012;15(1):18-25. DOI: 10.4103/0971-9784.91473.

26. Singh G, Dhulkhed P, Gupta I, et al. Evaluation of oral pregabalin premedication for attenuation of Pressor response during laryngoscopy and endotracheal intubation-A randomised clinical study. J Med Sci Clin Res 2016;4(12):14516-14525. DOI: 10.18535/jmscr/ v4i12.37.

27. Eren G, Kozanhan B, Hergunsel O. Pregabalin blunts cardiovascular responses to laryngoscopy and tracheal intubation. J Anesthesiol Reanim 2009;7:82-87. 